\title{
Destruction of conspecific bioturbation structures by Amphiura filiformis (Ophiuroida): evidence from luminophore tracers and in situ time-lapse sediment-profile imagery
}

\author{
Ronan O'Reilly, Robert Kennedy* ${ }^{*}$ Adrian Patterson
}

Zoology Department, Martin Ryan Marine Science Institute, National University of Ireland, Galway, Ireland

\begin{abstract}
Bioturbation processes of a dense ophiuroid assemblage were studied by in situ time-lapse sediment-profile imagery (t-SPI) and laboratory tracer-experiments. The burrows of 4 Amphiura filiformis (Ophiuroida) individuals were visible throughout the t-SPI deployment. Mean burrow excavation was $2.9 \mathrm{~cm}^{2} \mathrm{~h}^{-1}$. Mounding ranged from 0 to $7.12 \mathrm{~cm}^{2} \mathrm{~h}^{-1}$. Loss of sediment from the sediment-water interface ranged from 0 to $7.0 \mathrm{~cm}^{2} \mathrm{~h}^{-1}$. Bioturbation at the station was dominated by A. filiformis, whose presence appeared to mask the activity of conspecifics. Species interactions were investigated in terms of particle reworking by laboratory luminophore-tracer experiments of monocultures and species mixtures using A. filiformis, Leptopentacta elongata (Holothuroida) and Nephtys hombergii (Polychaeta). Bioturbation by these large species fit a symmetric non-local model well. Species interactions led to underyielding with respect to predicted additive species-effects. Treatments containing A. filiformis were significantly different from treatments without $A$. filiformis, and not significantly different from each other. When the data was processed on a per capita basis, multiculture treatments containing $N$. hombergii underyielded due to the high biomass of $N$. hombergii and its relatively low bioturbation activity. Ordination of a distance matrix derived from tracer profiles showed that tracer profiles produced by multispecies treatments were most similar to the strongest bioturbator, due to destruction of conspecific structures by the strongest bioturbator. Species interactions are not additive in terms of particle bioturbation, and may be difficult to predict without knowing in situ densities.
\end{abstract}

KEY WORDS: Sediment-profile imagery $\cdot$ Non-local modelling $\cdot$ Bioturbation $\cdot$ Species interactions $\cdot$ Amphiura filiformis

- Resale or republication not permitted without written consent of the publisher

\section{INTRODUCTION}

Amphiura filiformis has been described as a key species in coastal, muddy, fine sands, traditionally in terms of numerical dominance (Rosenberg 1976, 1995, O'Connor et al. 1983, 1986a,b, Josefson 1995, Kennedy et al. 2002), and also in a bioturbational role as ecosystem engineer (Solan \& Kennedy 2002). Ecosystem engineers are species that modify, maintain and create habitats and, through their actions, affect other species (Lawton 1994, Levinton 1995). During a time-lapse sediment-profile imagery (t-SPI) deployment at the station used in this study, Solan \& Kennedy (2002) found that the majority of biogenic structures that occurred in the sediment could be directly linked to the bioturbation activities of $A$. filiformis, which masked the bioturbation signatures of the rest of the assemblage. Rowden et al. (1998) found a significant relationship between the water content of the upper $5 \mathrm{~cm}$ of the sediment matrix and the abundance of A. filiformis, while Vopel et al. (2003) found that A. filiformis was responsible for up to $80 \%$ of oxygen flux into the sediment. Gilbert et al. (2003) described the particle-reworking mode of $A$. filiformis to be nonlocal on the scale of the mixed layer, i.e. particles are moved between 2 points that are not adjacent to each 
other (Boudreau 1986), and would lead to the rapid homogenisation of the sedimentary matrix. Non-local transport occurred in the arm tunnels, while local mixing occurred during disc-chamber formation and burrow maintenance. This study employs the same tracer as Gilbert et al. (2003). Local and non-local transport are scale (and therefore tracer)-dependent terms (Meysman et al. 2003).

Here we report a prolonged in situ, non-destructive observation of an equilibrium-stage assemblage dominated by the ophiuroid Amphiura filiformis in the inner Galway Bay, and investigate the effect of $A$. filiformis on the persistence of bioturbation traces within the sediment matrix using time-lapse sediment-profile imagery (t-SPI). We used luminophore tracers to evaluate the interaction of $A$. filiformis with selected conspecifics.

\section{MATERIALS AND METHODS}

Study area. Galway Bay is a westward-facing embayment on the west coast of Ireland. The site sampled in the inner bay (Margaretta; $53^{\circ} 13.50^{\prime} \mathrm{N}$, $09^{\circ} 06.50^{\prime} \mathrm{W}$ ) lies in $22 \mathrm{~m}$ of water, $5.6 \mathrm{~km}$ from the Corrib outfall at Galway Docks. Sediments are muddy, fine sands, with an organic content of approximately $1 \%$ by loss on ignition and surficial porosity of 22 to $38 \%$ (Kennedy et al. 2002). Predicted mean spring and neap tidal ranges in Galway Bay are 4.3 and $1.9 \mathrm{~m}$ respectively. Peak tidal velocities are in the order of $60 \mathrm{~cm} \mathrm{~s}^{-1}$ at the station. Tidal currents in the bay lead to a cycle of deposition and resuspension of fine material in the inner bay (Keary \& Keegan 1975). The subtidal benthic macrofaunal communities of the inner bay have been extensively documented (see, inter alia, O'Connor et al. 1993). The area surrounding Margaretta has been described as a Melinna palmata (Ampharetidae: Polychaeta) association of Peterson's (1913) Amphiura spp. community (Keegan et al. 1976), and has been classified as a stable, fully developed, 'normal' sere sensu Pearson \& Rosenberg (1978) (Keegan et al. 2002).

Methods. An SPI 2 sediment-profile camera system (Marine Technical Development Services) was deployed at the Margaretta station from the RV 'Conamara' on 16 September 2002 at high tide. The timelapse interval was $15 \mathrm{~min}$. The system was deployed for a total sampling period of $86 \mathrm{~h}$.

Image-analysis: Images were saved as 1520 by 1008 pixel, 24 bit, colour uncompressed TIFFs (tagged image file format). The area of the apparent redox potential discontinuity (aRPD) was determined by 8-way connected component labeling (Moga \& Gabbouj 1997) in 'Image Analyst 9.0.3' (RVSI Europe). The sediment-water interface was drawn manually in all images.
Measurements of burrow area, distance between individual burrows and the area of sediment ejected to the surface by Amphiura filiformis were taken in each image using Adobe Photoshop 6.0. The rates of discchamber construction and destruction were measured as change in area of the chamber visible against the faceplate of the camera. A similar measure was used to determine the rates of mound formation and dispersion on the sediment surface. A calibration point was set at a fixed depth in the sediment to compensate for settlement of the lander $\left(0.74 \mathrm{~cm} \mathrm{~d}^{-1}\right)$

Tracer experiments: Particle-reworking tracer experiments were performed on selected species in defaunated sediments. Sediment and animals were collected using a $0.1 \mathrm{~m}^{2}$ van Veen grab from the Margaretta station for the experiments. Microcosms were $93 \mathrm{~mm}$ internal diameter polycarbonate tubes with $15 \mathrm{~cm}$ of sediment and $18 \mathrm{~cm}$ overlying water. The microcosms were incubated at ambient temperature and salinity $\left(14^{\circ} \mathrm{C}\right.$ and $33 \mathrm{psu}$ ). We spread $1 \mathrm{~g}$ of luminophore particles (stained natural sediments that fluoresce in ultraviolet light: Mahaut \& Graf 1987) in the size class 90 to $125 \mu \mathrm{m}$ evenly on the sediment surface of each core. Experiments were incubated for $25 \mathrm{~d}$. At the end of the experiment, the sediment was vertically sectioned using a screw-piston device. The top $1 \mathrm{~cm}$ was sectioned in $5 \mathrm{~mm}$ slices. The remainder of the sediment was sectioned into $1 \mathrm{~cm}$ slices to a depth of $8 \mathrm{~cm}$. The 90 to $125 \mu \mathrm{m}$ fraction was removed by mechanical sieving and a subsample for tracer enumeration was taken from each core slice. Luminophore counts were normalised to the total recovered from each microcosm and processed as relative concentrations.

Species used in the experiment were Amphiura filiformis (Ophiuroida), Leptopentacta elongata (Holothuroida) and Nephtys hombergii (Polychaeta). All possible combinations of the species were used as treatments and replicated 3 times. Each individuals was measured before being added to the microcosms. A regression analysis of length and biomass of formalin-fixed specimens of each species was performed using specimens collected concurrently for a benthic survey (Kennedy et al. 2002). Species were added to the microcosms at as close to natural density as possible. All treatments containing $A$. filiformis had 6 individuals of that species, those containing $N$. hombergii had 3 individuals and those containing $L$. elongata had 1 individual.

Non-local transport coefficients were calculated using the symmetric non-local model of Solan et al. (2004b):

$$
\frac{\partial C}{\partial t}=\int_{0}^{\infty} K\left(z^{\prime}, z\right) C\left(z^{\prime}, t\right) \mathrm{d} z^{\prime}-\int_{0}^{\infty} K\left(z^{\prime}, z\right) C\left(z^{\prime}, t\right) \mathrm{d} z^{\prime}
$$

where $K\left(z^{\prime}, z\right)$ represents the exchange function (Boudreau 1986, Boudreau \& Imboden 1987, Meysman 
et al. 2003) that models the displacement rate of luminophores from a depth $z^{\prime}$ to the depth $z$. The exchange function was assumed to be symmetric and to decrease exponentially with increasing distance, i.e.

and

$$
K\left(z^{\prime}, z\right)=K\left(z, z^{\prime}\right)
$$

$$
K\left(z^{\prime}, z\right)=\operatorname{aexp}\left(-\frac{\left|z-z^{\prime}\right|}{\lambda}\right)
$$

where $a$ is a reworking activity constant (dimensions $\mathrm{L}^{-1} \mathrm{~T}^{-1}$ ), and $\lambda$ is the attenuation constant of the exponential function (dimension $\mathrm{L})(\mathrm{L}=$ sediment depth, $\mathrm{T}=$ time).

The fixed exchange-function was the same as that used by Solan et al. (2004b) to describe reworking observed in a t-SPI deployment in a community similar to that in our study area. Solan et al. (2004b) were able to describe rapidly fluctuating rates of visible tracer redistribution at $10 \mathrm{~min}$ intervals. Here, we used a standardised exchange-function so that species were compared only in the magnitude of sediment reworking, and a comparable univariate response would be produced. We used a fixed attenuation depth of $\lambda=$ $10 \mathrm{~cm}$ so that different treatments would be directly comparable. This scale was larger than the total length of the transport observed and, given the shallow scale of consideration ( 0 to $8 \mathrm{~cm}$ ), the model provided a good description of particle reworking.

Particle redistribution was modelled by Eq. (1) using the initial condition of an instantaneous source of unit strength at $t=0$ and $z=0$. The tracer profiles were modelled as a closed system, with no tracers being buried below the mixed layer. Boundary conditions were:

Upper boundary condition: $\left.\frac{\partial C}{\partial z}\right|_{z \neq 0}=0$

Lower boundary condition: $\left.\frac{\partial C}{\partial z}\right|_{z \geq L}=0$

where $L$ represents the depth of the modelled sediment $(8 \mathrm{~cm})$. The values of $a$ producing the best fit were determined by weighted least-squares regression (François et al. 2002) using steepest-descent optimisation (Press et al. 1986). This procedure calculates a squared residual between the observed $\left(\mathrm{obs}_{i}\right)$ and calculated $\left(\right.$ calc $\left._{i}\right)$ concentrations at each depth. Each residual is weighted by the corresponding observed concentration plus 1, to prevent a null denominator. A regression coefficient ( $\mathrm{r}$ ) is calculated by summing the residuals:

$$
\mathrm{r}=\sum_{i=1}^{n} \frac{\left(\mathrm{obs}_{i}-\mathrm{calc}_{i}\right)^{2}}{\mathrm{obs}_{i}+1}
$$

where $i$ denotes the ith depth interval or core slice. The procedure attempts to give due consideration to the deeper sediment layers, where values of tracer concentration are typically low relative to the surface layers. Where the calculated profile is a perfect match with the observed profile, $r=0$.

The regression coefficients (r) were compared by 1-way ANOVA to determine if there was any significant difference between the fit produced by the standardised exchange-function and the observed profiles produced by the different species-combinations.

Diversity effects on ecosystem processes have traditionally been investigated using relative yield in short-term experiments of substitutive design in which biomass has been kept constant (Hector 1998, Hector et al. 1999, Loreau 1998, Houston et al. 2000, Jolliffe 2000). Diversity effects using relative yield have largely focused on productivity in terrestrial plants. Similar work in marine benthic invertebrates has focused on small species of similar size that typically occur in high densities in intertidal mudflats (Emerson et al. 2001, Raffaelli et al. 2003). In other studies using animals of greatly unequal size and density, biomass or abundance has been maintained at separate levels (Heemsbergen et al. 2004, Mermillod-Blondin et al. 2005). Here, we maintain a separate level of biomass for each species, representing the natural density found in Galway Bay.

A 1-way analysis of variance was performed using species composition as the factor and the calculated reworking activity constant a as the response, and post hoc, pairwise comparison by Tukey's family error-rate test.

The expected effect of a species mixture on reworking activity was the sum per capita effects of the component species (Hector 1998, Raffaelli et al. 2003). Per capita rates were calculated by dividing the best fit value of $a$ by the biomass of the animals used in the treatment in grams, i.e. per capita effects represent the effect of $1 \mathrm{~g}$ biomass in a given treatment. For the sake of comparison, the effect of species interaction in natural densities (biomass) was also examined:

$$
E(i+j)=E(i)+E(j)
$$

where $E(i)$ is the effect of Species $i$ in monoculture, $E(i+j)$ is the effect of Species $i$ and Species $j$ in biculture.

Calculated values of a were calculated for all possible combinations of the observed monoculture responses. For example, there were $3 \times 3$ possible predicted values of $E(A f+N h)$ based on 3 observed values each of $E(A f)$ and $E(N h)$ ( $A f=$ Amphiura filiformis, Nh $=$ Nephtys hombergii).

Observed and predicted values of a for the multispecies treatments were compared by 1-way ANOVA and post hoc Tukey's test. A significant difference was taken to indicate a species interaction effect on ecosystem process. 
Each observed tracer profile was regressed against every other observed tracer profile by Eq. (6). The r-values were used to produce a distance matrix that was processed by ordination techniques to produce a multidimensional scaling (MDS) plot (Kruskal \& Wish 1978). Points close to each other on the MDS plot represent microcosms that yielded similar tracer plots.

\section{RESULTS}

The deployment of the SPI camera acquired a total of $86 \mathrm{~h}$ of time-lapse footage at the Margaretta station. The proximity of the camera appeared to have no adverse effects on faunal activity, with infaunal activity (i.e. Amphiura filiformis arms) evident from the first image onwards. Near-bed current flow did not appear to be affected by the presence of the SPI camera, and there was no apparent increase in sedimentary erosion or deposition at the sediment-water interface due to the camera. The presence of burrows and oxic voids was quickly re-established by the second image, approximately 17 min after camera deployment.

Prism penetration depth was shallowest in the first image at a depth of $13.13 \mathrm{~cm}$, increasing throughout deployment until penetration was at its greatest in the penultimate image at $15.78 \mathrm{~cm}$. Mean penetration depth was $15.23 \mathrm{~cm}$. Some small variations in the penetration depth, such as minor intervals of decreasing depth, were due to topographical changes at the sediment water interface by infaunal and epifaunal activity.

The depth of the apparent redox potential discontinuity (aRPD) fluctuated during the course of deployment, with the deepest mean aRPD being $6.98 \mathrm{~cm}$ and the shallowest $6.07 \mathrm{~cm}$. The average aRPD depth over the course of the deployment was $6.58 \mathrm{~cm}$.

Epifauna were intermittently evident throughout deployment, occurring in $22 \%$ of the images, with Necora

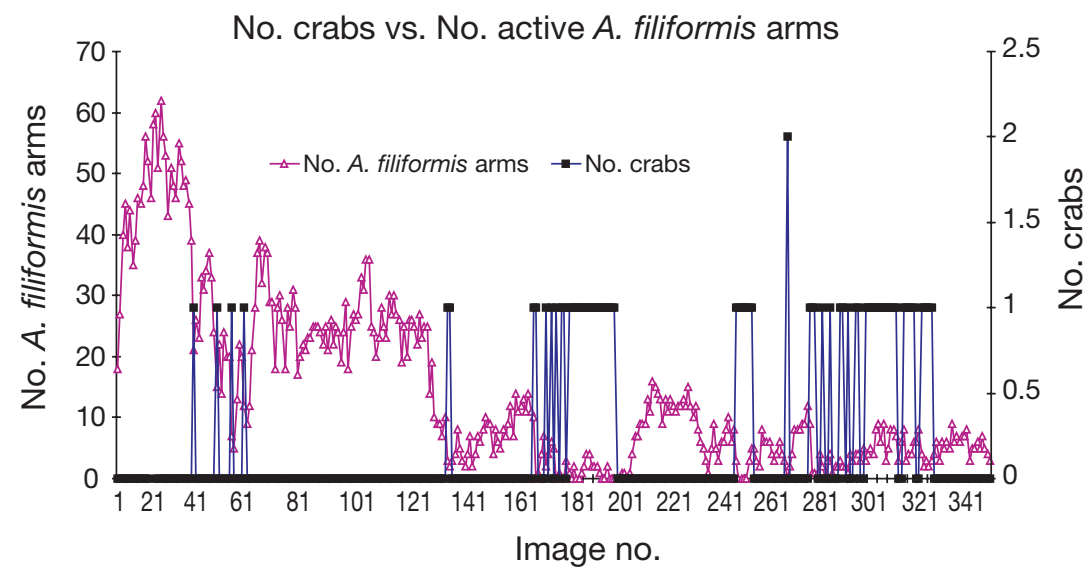

Fig. 1. Amphiura filiformis. Number of arms active at surface compared to crab (Necora puber) activity throughout deployment puber (the purple, velvet swimming crab) being the dominant epifaunal species. The presence of this species caused retraction of the Amphiura filiformis arms that were extended out of the sediment (Fig. 1).

\section{Animal sediment relations}

Throughout deployment, 4 individual Amphiura filiformis excavations (Fig. 2) were evident. The depth of the various disc chambers in the sediment changed over time, with individuals moving both vertically and horizontally in the sediment. The shallowest disc chamber occurred at $2.0 \mathrm{~cm}$ and the deepest chamber was maintained at $6.8 \mathrm{~cm}$. An approximate distance of $6.3 \mathrm{~cm}$ was maintained between disc chambers at the same depth, except in the case of a chamber being actively moved. The 4 disc chambers were arranged with 2 shallow chambers (A and B) maintained at an approximate depth of $2.0 \mathrm{~cm}$, and 2 deep chambers (C and D), at an approximate depth of $6.5 \mathrm{~cm}$ (Fig. 2). The disc chambers were arranged in an alternating pattern of 1 shallow and 1 deep. The mean disc-chamber depth in the sediment, area and rates of formation and destruction for all 4 burrows, together and individually, are shown in Table 1. Fig. 3 shows the disc-chamber area for each burrow individually, and all 4 together in each image over period of the deployment.

Burrowing activity occurred in all images, with the rates of disc-chamber construction and destruction alternating, depending on the dominant process. The greatest area of visible disc-chamber void in an image was $240.69 \mathrm{~mm}^{2}$ in Image 125 . The greatest rate of discchamber construction occurred in Image 125, with a total area of $162.14 \mathrm{~mm}^{2}$ of sediment being removed from in front of the faceplate. The average rate of disc chamber construction per image was $11.49 \mathrm{~mm}^{2}$ $\left(45.96 \mathrm{~mm}^{2} \mathrm{~h}^{-1}\right)$. The greatest rate of disc-chamber destruction occurred in Image 126, with collapse refilling-in a total area of $153.17 \mathrm{~mm}^{2}$ of sediment. The average rate of disc-chamber destruction per image was $10.96 \mathrm{~mm}^{2}\left(43.84 \mathrm{~mm}^{2} \mathrm{~h}^{-1}\right)$. The total area of sediment moved over the entire deployment, from both discchamber construction and destruction was $7749.06 \mathrm{~mm}^{2}$. The total area of sediment excavated by Amphiura filiformis was $3964.56 \mathrm{~mm}^{2}$. Burrowing activity was dominated by 2 individuals (Fig. 3a,d) whose activity was evident throughout the majority of the deployment. The first individual maintained a disc chamber near the surface at an average depth of $2.9 \mathrm{~cm}$ (Disc Chamber 

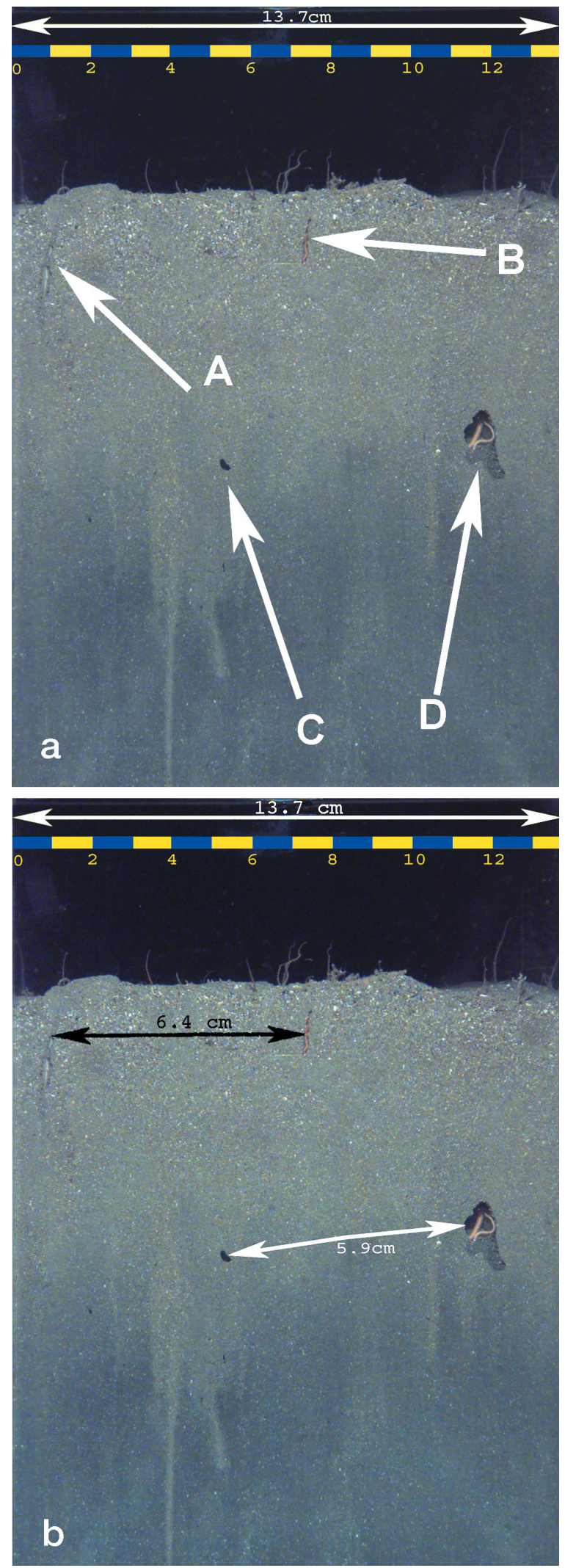

Fig. 2. Amphiura filiformis. (a) 4 disc chambers A, B, C, D; (b) relative spacing of burrows
Table 1. Mean depth $(z)$, mean disc-chamber (DC) area and mean rates of disc-chamber formation and destruction, for individual disc chambers (A to D) and combined data (All)

\begin{tabular}{|lcrcc|}
\hline DC & $\begin{array}{c}z \\
(\mathrm{~cm})\end{array}$ & $\begin{array}{c}\text { Area } \\
\left(\mathrm{mm}^{2}\right)\end{array}$ & $\begin{array}{c}\text { Formation } \\
\text { area }\left(\mathrm{mm}^{2} \mathrm{~h}^{-1}\right)\end{array}$ & $\begin{array}{c}\text { Destruction } \\
\text { area }\left(\mathrm{mm}^{2} \mathrm{~h}^{-1}\right)\end{array}$ \\
\hline A & 2.9 & $13.29 \pm 1.69$ & 16.84 & 15.04 \\
B & 2.0 & $6.71 \pm 0.85$ & 4.60 & 4.48 \\
C & 6.3 & $10.38 \pm 0.94$ & 3.24 & 3.04 \\
D & 6.8 & $43.59 \pm 3.91$ & 21.24 & 21.20 \\
All & - & $73.99 \pm 4.59$ & 45.96 & 43.84 \\
\hline
\end{tabular}
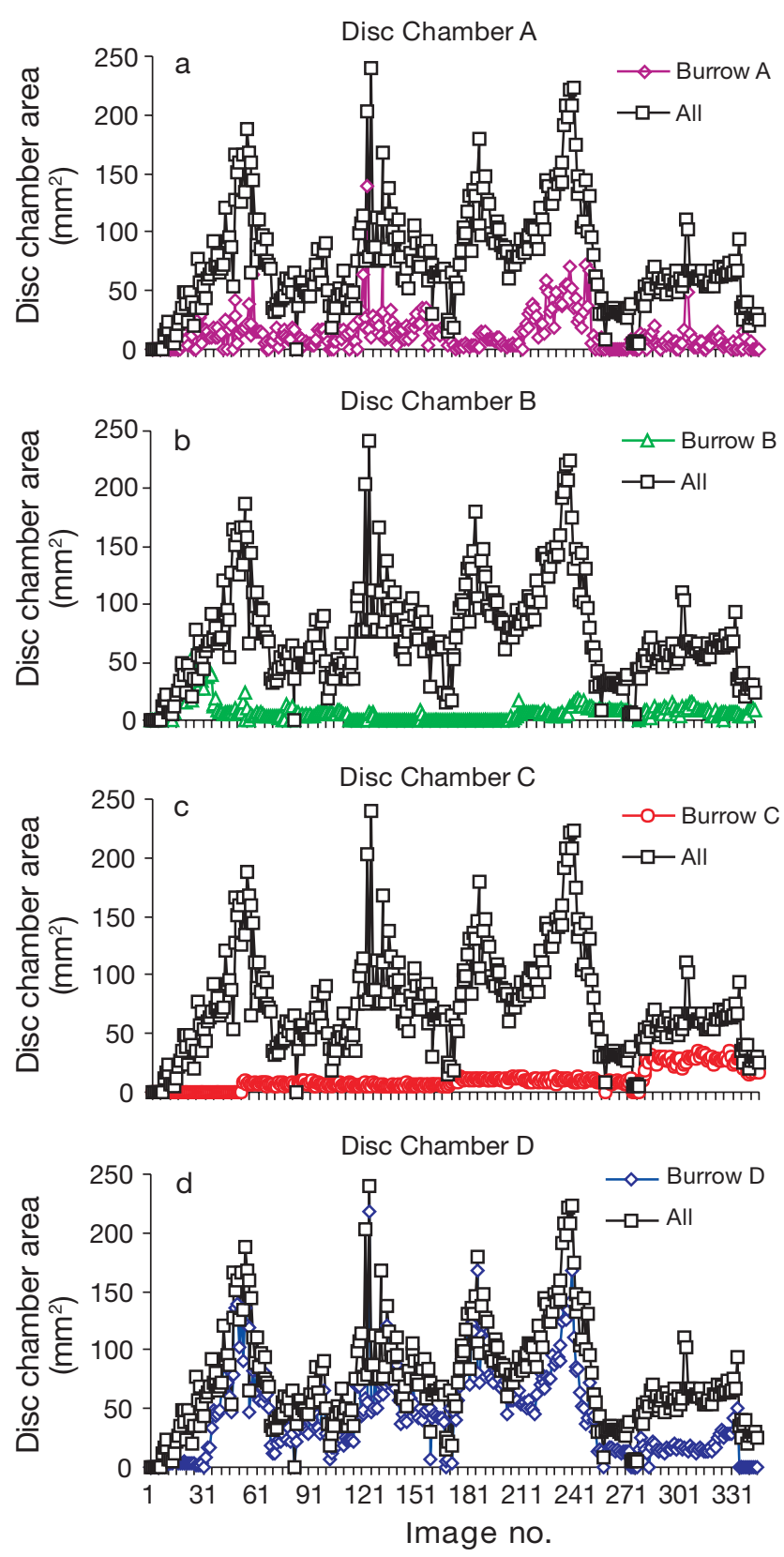

Fig. 3. Amphiura filiformis. Change in disc-chamber area for each disc chamber compared to change in area for the whole image over throughout deployment 
A), perpendicular to the faceplate of the prism, and most of the visible activity varied between disc-chamber maintenance and feeding. The second individual maintained its disc chamber at an average depth of 6.8 $\mathrm{cm}$ (Burrow D), and visible activity consisted of discchamber construction and maintaince, with no visible period spent feeding at the surface. The remaining 2 disc chambers (B and C) made up only a small proportion of overall activity and were maintained at average depths of 2.0 and $6.3 \mathrm{~cm}$ into the sediment respectively.

The visible area of Disc Chamber A varied from $0 \mathrm{~mm}^{2}$ in a number of images to $138.52 \mathrm{~mm}^{2}$ in Image 123 over the period of deployment. The total area of sediment moved from Disc Chamber A over the entire length of deployment, from both burrow construction and destruction, was $2754.68 \mathrm{~mm}^{2}$, with the disc chamber being completely refilled by the end of the deployment. Disc Chamber B attained a maximum area of $60.75 \mathrm{~mm}^{2}$ in Image 278. A total area of $787.09 \mathrm{~mm}^{2}$ of sediment was moved in Chamber B during deployment, with the chamber being refilled by the end of deployment. Disc Chamber $C$ reached a maximum size of $34.83 \mathrm{~mm}^{2}$ in Image 329. Burrow construction and destruction moved $543.66 \mathrm{~mm}^{2}$ of sediment in Disc Chamber C during deployment. Disc Chamber D reached its maximum area in Image 125 , with an area of $218.4 \mathrm{~mm}^{2}$. The total area of sediment excavated from Disc Chamber D was $1831.80 \mathrm{~mm}^{2}$. The total area of sediment moved from Disc Chamber D throughout the entire deployment, from construction and destruction, was $3663.61 \mathrm{~mm}^{2}$.
The active burrowing element of Disc Chamber D moved a total distance of $3.9 \mathrm{~cm}$ through the sediment, moving both horizontally and vertically (Fig. 4).

Brittle-stars feeding at the surface were evident in high numbers, with Amphiura filiformis arms being the most conspicuous. Arms can be seen extended from the 2 upper $A$. filiformis disc chambers (A and B), while the individuals in the 2 deeper disc chambers $(C$ and D) did not appear to feed at the surface at any time. Feeding activity at the surface would appear to be continuous, with the arms being fully extended into the water column for prolonged periods (Fig. 5a). This retraction of the arms appears to be linked with the appearance of predators, in this case Necora puber. As a response to the approach of predators the arms appear initially to be partially withdrawn, with only a small part of the arm visible above the surface (Fig. 5b). As the predator moves directly above the arms they are completely withdrawn below the sediment surface (Fig. 5c) and do not reappear until the predator has departed. The brittel-stars deeper in the sediment do not appear to feed at the surface, but would appear to scavenge for food at depth. This is particularly evident for the individuals in Disc Chamber D, whose movement was recorded throughout deployment, with a large amount of sediment being moved in the process.

Mounding was evident throughout the deployment and particularly for the durations when Amphiura filiformis arms were active on the surface. Material
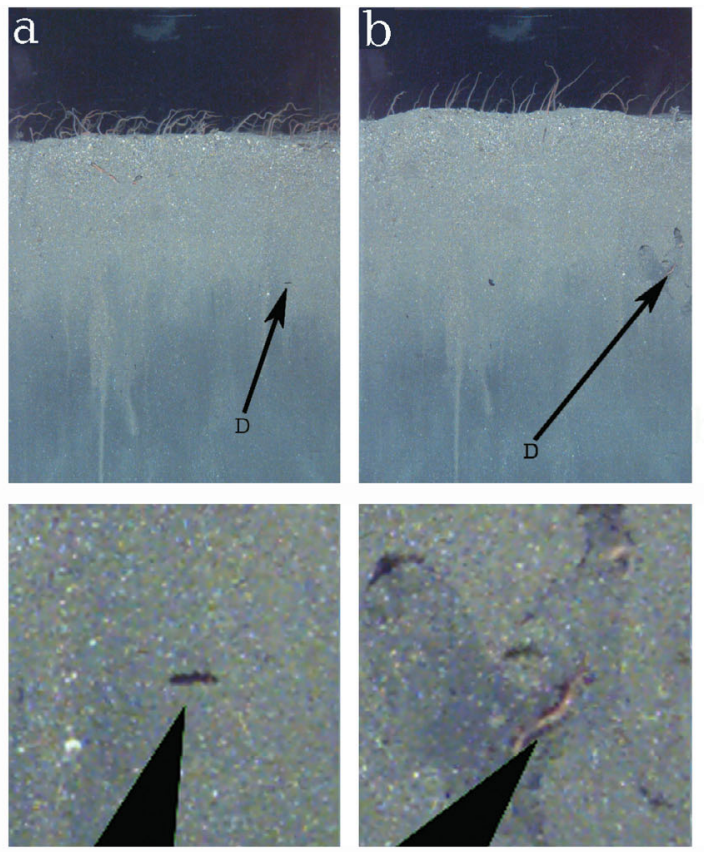
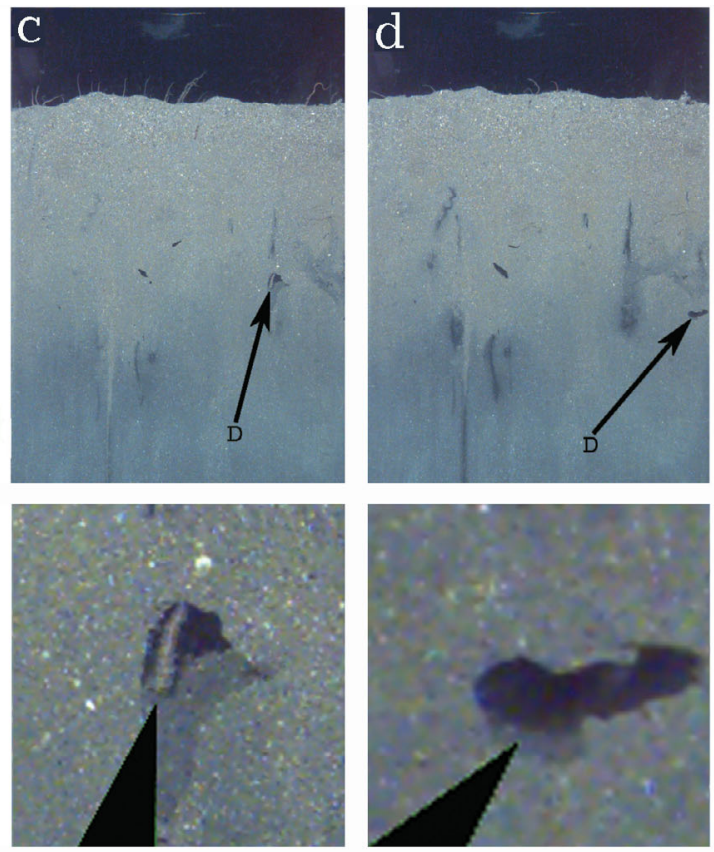

Fig. 4. Amphiura filiformis. Progress of Disc Chamber D as brittle-star moves through sediment. (a) Initial disc-chamber formation; (b to d) movement of disc chamber deeper into sediment. Depth of penetration of camera also increases over time. Lower panels are enlargements of area around disc chambers 

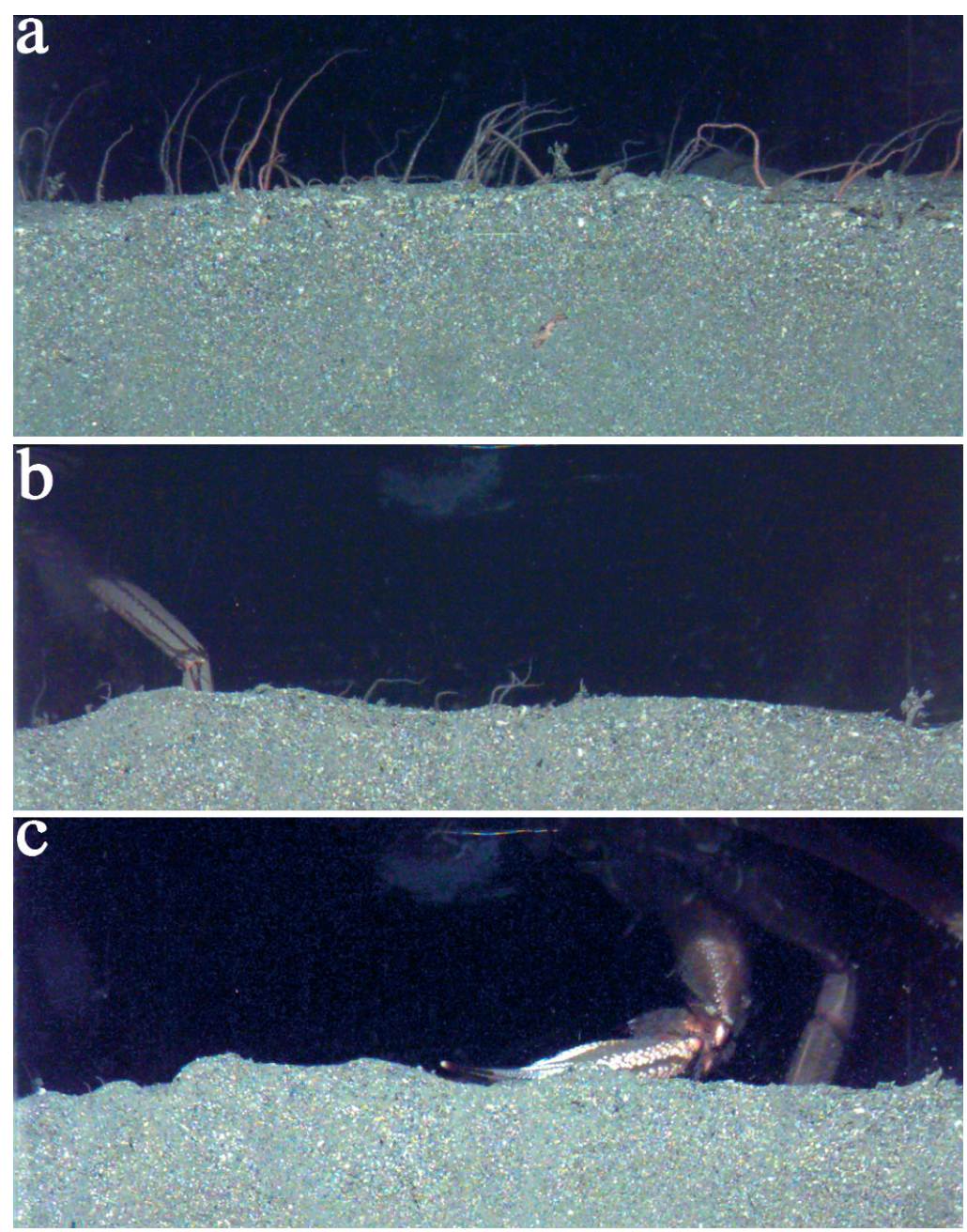

Fig. 5. Amphiura filiformis. Arm withdrawal response of brittle-star feeding at surface to approach of predator Necora puber

\section{Tracer experiments}

Fig. 7. shows the mean observed and calculated results for each treatment. No observed profile was strongly nonlocal or showed marked subsurface maxima, but the non-local model fit the data better than a 1-dimensional bio-diffusion model (Kennedy 2000). A 1-way ANOVA of the regression coeffiecients (r) using treatment as the factor revealed no significant difference between the fit of the calculated profiles to the observed profiles of the different species-combinations using the standardised exchange-function (Table 2). Amphiura filiformis produced the greatest values of $a$ in monoculture, followed by Leptopentacta elongata, while Nephtys hombergii produced the smallest values

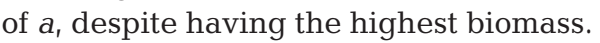
This was the case for both per capita and natural-density data.

The 1-way analysis of variance for the per capita microcosm (Fig. 8a) experiments split the treatments into 2 distinct groups: 1 that contained Nephtys hombergii, and 1 that did not $(\mathrm{p}<0.001)$. The 1 -way analysis of variance for the natural-density populations (Fig. 8b) revealed 3 distinct treatment groups: 1 that contained Amphiura filiformis, 1 that contained Leptopentacta elongata but not $A$. filiformis, and 1 that contained $N$. hombergii only $(\mathrm{p}<0.001)$. appeared to be moved from beneath the sediment water interface and deposited around the exit points of the arms. The resulting mounds were disturbed by persistent arm activity and did not often form the typical conical shape associated with $A$. filiformis excavations (Solan \& Kennedy 2002). As a result, the number of mounds recorded from analysing the single images did not reflect the true rate of mounding by biogenic activity. Loss of excavated sediment from the surface also occurred. The rate of sediment loss from the sediment- water interface ranged from 0 to $7 \mathrm{~cm}^{2} \mathrm{~h}^{-1}$. These values do not represent the true rate of sediment excavation to the surface or loss of sediment from the interface as both processes occur at the same time and Fig. 6 only shows the net rate of gain or loss.

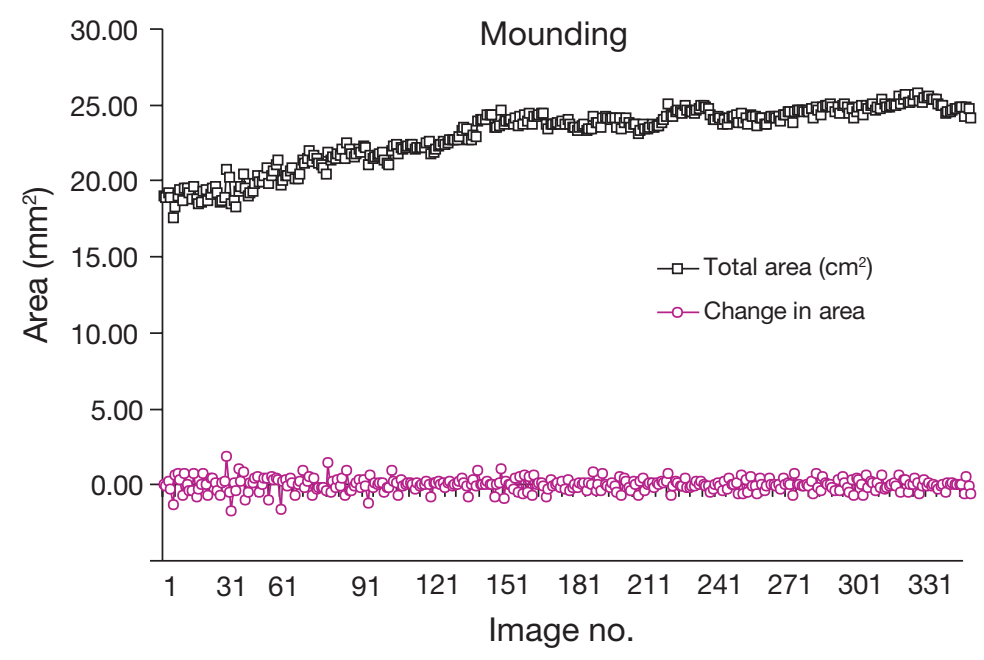

Fig. 6. Amphiura filiformis. Overall rate of mounding against the camera faceplate per image, and change in rate of mounding between images $\left(\right.$ area $\mathrm{cm}^{2}$ ) 

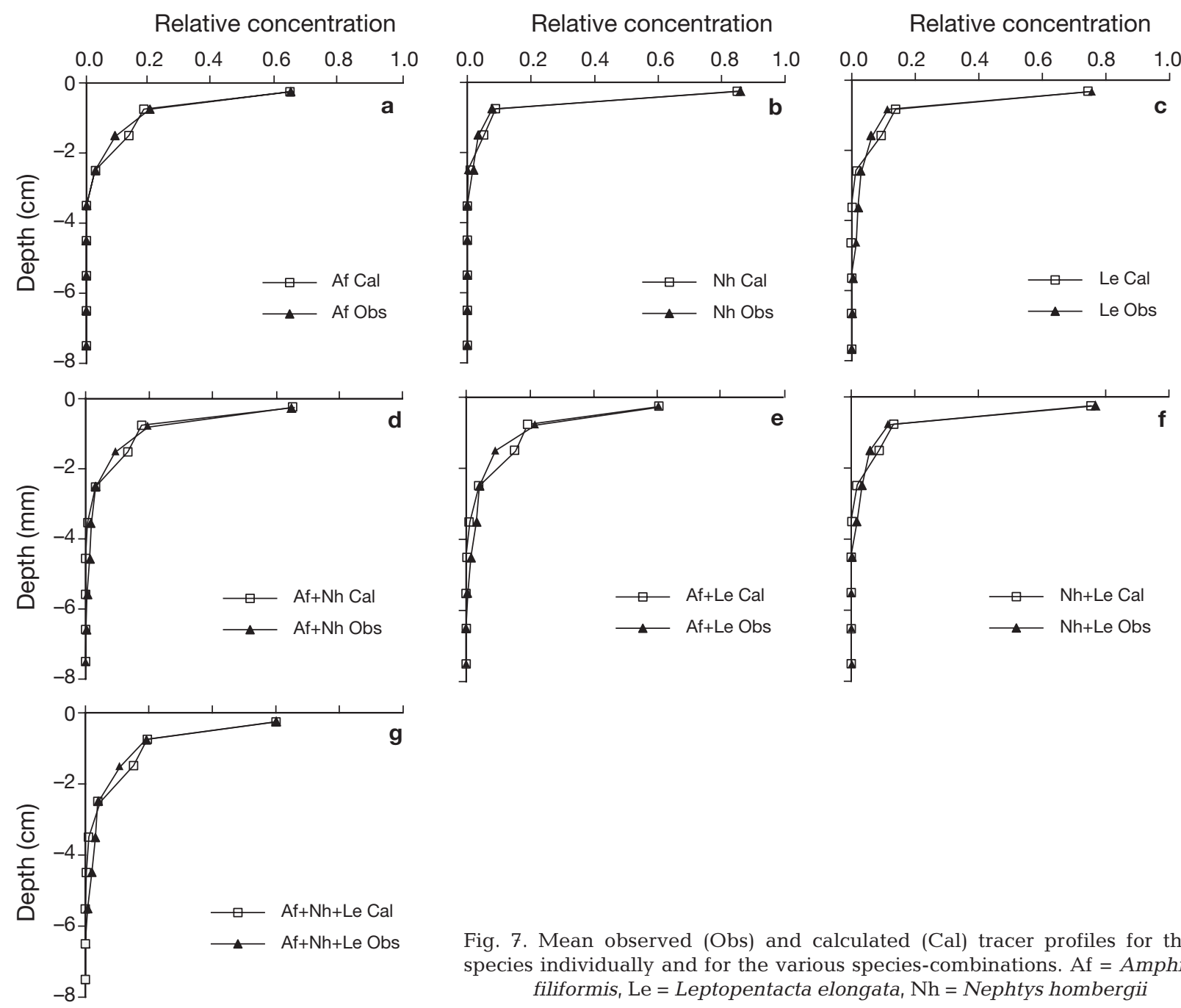

Fig. 7. Mean observed (Obs) and calculated (Cal) tracer profiles for the 3 species individually and for the various species-combinations. Af = Amphiura filiformis, Le $=$ Leptopentacta elongata, $\mathrm{Nh}=$ Nephtys hombergii

The predicted effect of the species mixtures on reworking activity was compared to the observed reworking rate by 1 -way analysis of variance for each treatment. For both the per capita and natural-density experiments, each treatment underyielded from the predicted reworking rate, i.e. the sum effect of the component species (Hector 1998, Raffaelli et al. 2003), p < 0.001 for all treatments.

Table 2. Amphiura filiformis, Leptopentacta elongata and Nephtys hambergii. 1-way ANOVA of regression coefficients (r) using species-combination treatment as factor

\begin{tabular}{|lcrccc|}
\hline & SS & df & MS & \multicolumn{1}{c|}{$F$} & p \\
\hline Between treatments & $3.835 \mathrm{E}-05$ & 6 & $6.392 \mathrm{E}-06$ & 2.639 & 0.063 \\
Within treatments & $3.392 \mathrm{E}-05$ & 14 & $2.423 \mathrm{E}-06$ & & \\
Total & $7.227 \mathrm{E}-05$ & 20 & & & \\
\hline
\end{tabular}

The MDS ordination (Fig. 9) of the distance matrix placed the treatments into 3 distinct groups: (1) treatments with Amphiura filiformis present, (2) treatments with Leptopentacta elongata present but not A. filiformis, and (3) the treatment containing only Nephtys hombergii.

\section{DISCUSSION}

During the course of the camera deployment, activity in the sediment was dominated by the 4 active disc chambers of Amphiura filiformis, and these accounted for the majority of sedimentary transport and excavation to the surface. As noted by Solan \& Kennedy (2002), the structure of the sediment appeared to be determined by the bioturbation and feeding activities of $A$. filiformis. The position of Disc Chambers A, B and C remained remarkably constant throughout the deployment. Cham- 


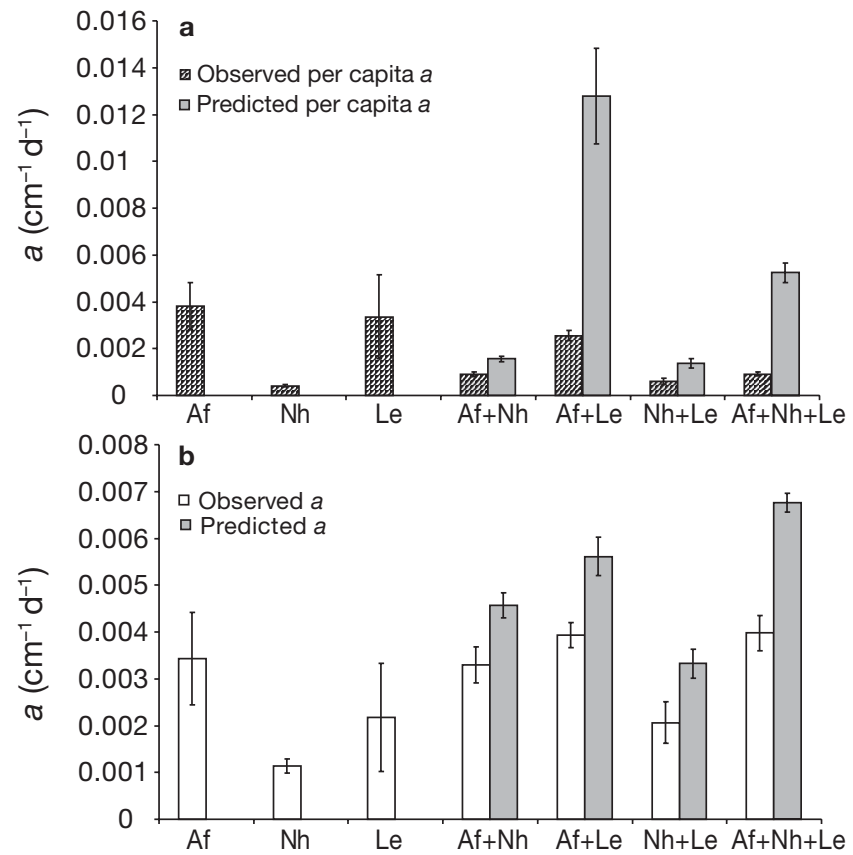

Fig. 8. Observed and predicted results for each treatment for (a) per capita and (b) natural-density population. Af $=A m$ phiura filiformis, Le $=$ Leptopentacta elongata, $\mathrm{Nh}=$ Nephtys hombergii

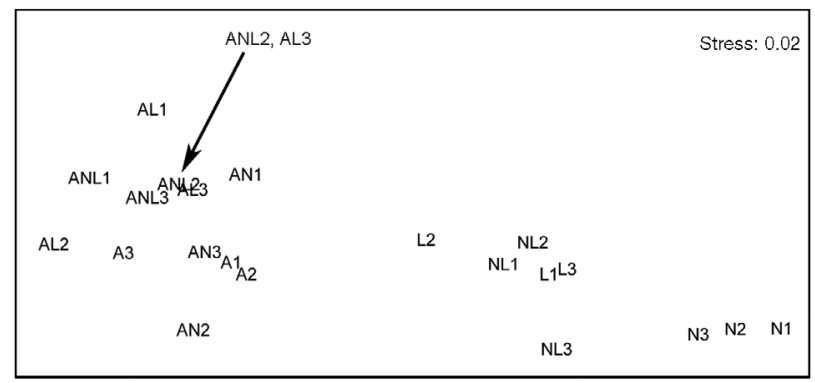

Fig. 9. MDS ordination of distance values derived from observed tracer profiles. $\mathrm{A}=$ Amphiura filiformis, $\mathrm{L}=$ Leptopentacta elongata, $\mathrm{N}=$ Nephtys hombergii

ber D moved throughout deployment, with the chamber being infilled behind the brittle-star's progress. The infilled material changed in colour from high-reflectance sediment to darker, partially reduced sediment towards the end of the deployment. This points to rapid utilisation of buried material by microbial diagenesis of labile carbon. The movement of surficial sediment from oxidised to reduced condition may be an important pathway in the early diagenesis of carbon in this area. Fig. 10b shows the occurrence of reduced material within the oxidised layer that was not evident at the beginning of deployment (Fig. 10a).

The positioning of the disc chambers, with the 2 uppermost occurring approximately $2 \mathrm{~cm}$ below the surface and horizontally separated by $6.4 \mathrm{~cm}$ and the 2
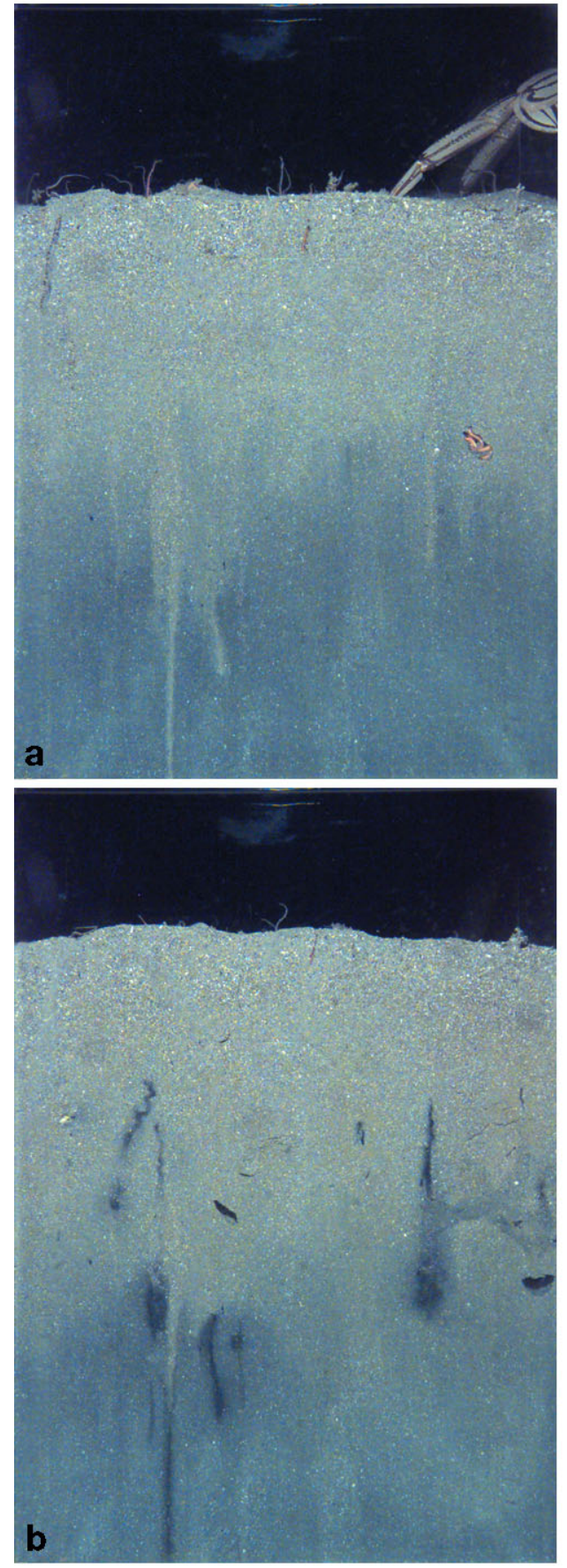

Fig. 10. Localised reduction of reworked oxidised sediment over the elapsed period of film (a) $t=1 \mathrm{~h}$, (b) $t=86 \mathrm{~h}$

deeper chambers occurring at approximately $6.5 \mathrm{~cm}$ and horizontally separated by $6.4 \mathrm{~cm}$, greatly increases the potential foraging and particle reworking area for each individual within the sediment. The brittle-stars in the upper stratum can be seen to actively forage at the surface with their arms directly extended into the water column, and they would also appear to deter- 
mine the rate of mounding and surface-boundary roughness. Mounding of material excavated by Amphiura filiformis on the surface did not form the conical shaped mounds described in a previous work at their station (Solan \& Kennedy 2002). This may be due to the fact that a diver SPI was used in the previous study, which caused a high degree of disturbance when being placed in the sediment and reduced the number of $A$. filiformis present. The material excavated at the surface is often redistributed over a larger area by other arms in the vicinity, producing a more even surface. The continuous excavation that occur during the periods when there is a high density of arms on the surface also contribute to this featureless surface, as features become blurred by the amount of material deposited on the surface. The foraging activities of Necora puber disturb the surficial sediments as this crab probes into the sediment with its forelimbs in search of food. This foraging activity of the crab was shown to play a key role in surficial sediment reworking in a time-lapse SPI deployment by Solan et al. (2004b). The short persistence-time of surface mounds may cause the rate of sediment excavation to be greatly underestimated. The ephemeral nature of biogenic mounds may reduce their suitability as a diagnostic feature in single-shot SPI deployments. Material was also lost from the sediment-water interface throughout the deployment. It is unclear whether the material loss was due to reburial by the infauna or by resuspension. Anecdotal evidence has been provided by a numbers of authors (Keary \& Keegan 1975, O'Connor et al. 1993) that a tidally driven cycle of temporary deposition and resuspension of fine materials occurs at the Margaretta station. Kennedy et al. (2002) report very high resuspension rates at the Margaretta station (150 g dry wt $\mathrm{m}^{-2} \mathrm{~d}^{-1}$, with a mean particle diameter of approx. $70 \mu \mathrm{m}$ ) Rowden et al. (1998) investigated the geotechnical properties of the sediment occupied by a similar community in the North Sea, and reported that Amphiura filiformis had a major impact on the susceptibility of the surficial sediments for resuspension.

Feeding in Amphiura filiformis did not appear to follow any fixed cycle; this may have been due to disturbance of the population by the appearance of the predator Necora puber. The pattern of feeding described in previous experimental laboratory observations (Buchanan 1964, Woodley 1975) and observations in the field (Solan \& Kennedy 2002) was not evident. The arms did follow the predictable morphological sequence of feeding during periods of strong current flow (Loo et al. 1996, Solan \& Kennedy 2002), but this activity was halted and the arms withdrawn into the sediment when predators appeared. The arms of A. filiformis are known to be a source of food for many fishes and invertebrate predators (van Duineveld \& Noort 1986, Baden et al. 1990). High concentrations of A. filiformis arms may have attracted $N$ puber. With the appearance of a predator, the arms of $A$. filiformis would retract until just the tips remained above the surface. As the predator passes directly over the arms, they are completely withdrawn below the sediment. It has been proposed that the initial response to the approach of a predator is triggered by tactile stimuli rather than predator recognition, and that a warning is propagated through the population by a mechanism such as chemoreception. Rosenberg \& Selander (2000) carried out a series of experiments to determine if there was an alarm response to predation in conspecifics of $A$. filiformis, and by which means the alarm signal was propagated. They found that $A$. filiformis responded to chemical signals released from damaged tissue in conspecifics, with the feeding arms of the neighbouring individuals bending to the surface and some withdrawing into the sediment. The response to the approach of a predator was clear during periods of the deployment, when a crab ( $N$. puber) could be seen approaching in the distance. At this point, a warning would appear to have been issued through the population as the arms in the foreground (well removed from the area of predation) were nearly completely retracted into the sediment. It was not until the predator then moved directly overhead that the arms were fully retracted. A. filiformis arms began to reappear in small numbers in the subsequent image (15 min), even if the predator had not moved off. This would suggest that the alarm response is chemical in nature and is quickly dissipated by bottom currents.

The use of t-SPI at this station has shown that Amphiura filiformis is the dominant species at this station. The physical and chemical nature of the sediments appears to be in the main determined by the biogenic activities of A. filiformis. In previous studies carried out at this station, it has been found to have a large and diverse community incorporating species such as Pholoe inornata, Mysella bidentata, Nephtys hombergii and Kefersteinia cirrata in high numbers, yet the presence and bioturbational signature of these species was not evident throughout the deployment of the camera. Their presence would appear to have been masked by A. filiformis, which also seems to dominate in determining the nature of the sediments and, as a result, may play a key role in determining community structure.

\section{Tracer experiments}

Bioturbation in all treatments was well-described by the symmetric non-local model. All the experimental species could have been expected to move particles 
over scales of centimetres, given their large size and tendency to construct temporary burrow structures. Burrow collapse and infill was likely to move particles over length scales approaching the body size of the animals (Boudreau \& Imboden 1987). Any attempt to produce a single univariate response from species that differ in terms of size, behaviour and biomass, enabling direct hypothesis testing, is likely to be divorced from the actual mechanistic reworking of some or all the species. Although there was no significant difference in the fit of the model between treatments in this study, it is likely that more mechanistically informed and flexible modeling of each treatment individually (both in terms of exchange function and attenuation coefficient) would yield valuable further information on the contribution of each species to net community bioturbation. Species may differ not only in the magnitude of reworking activity, but also in terms of the exchange function that best fits the tracer profiles they produce.

All multispecies treatments underyielded in terms of a, implying that there was facilitation in reworking activity on species interaction. This occurred in both the per capita and uncorrected data analysis. Similar results in terms of bioturbation processes have been found in other studies (Emerson et al. 2001, Raffaelli et al. 2003, Heemesbergen et al. 2004, MermillodBlondin et al. 2005). Because of the lack of constant biomass in our experiment it is not directly comparable to much of the preceding work aimed at determining the effects of diversity on ecosystem process. Density may have had an effect on the results of our analysis, but this is often not the case (Loreau \& Hector 2001). The focus of our work was rather on how the actual in situ densities of bioturbating species interact.

Reworking activity by Amphiura filiformis led to rapid dispersion of tracers throughout the upper $8 \mathrm{~cm}$ of the microcosms. Oxidised material was rapidly subducted to the reduced layer, while reduced material was ejected to the surface. Combined with the stratification of animal occupancy of the sediment, this may maximise the availability and utilisation of organic material in the sediment. Bioturbation by Leptopentacta elongata and Nephtys hombergii had significant effects on particle redistribution in monoculture, but at natural density the presence of $A$. filiformis masked the effects of these species. This rapid homogenisation and frequent turnover of surficial sediments may serve to exclude the larvae of competing species (Levinton 1995) and control community structure by disturbance (Austen \& Widdicombe 1998).

Underyielding was much stronger in the per capita data. This was largely due to the effect of Nephtys hombergii in multiculture with the other species. $N$. hombergii had the greatest biomass of the 3 species, but produced the smallest value of $a$. The inclusion of $N$. hombergii in bicultures treatments with Amphiura filiformis or Leptopentacta elongata at natural densities, produced results for a that were not significantly different from the Monoculture a for A. filiformis or $L$. elongata respectively. When the data is considered on a per capita basis, the a for the bicultures becomes significantly less than that for the monocultures of A. filiformis and L. elongata. Constraining biomass to standards may produce interaction results that, although informative in terms of species richness effect, have little relevance to the interactions of species in the field. All models of habitat quality and animal-sediment relations (and by association ecosystem processes), take account of species biomass as an important facet of the species' role in ecosystems (Pearson \& Rosenberg 1978, Rhoads et al. 1978). Biomass and density of species in natural stands are vital facets of the species functional role in the ecosystem. This is demonstrated by our 1-way ANOVAs. The dominance of $A$. filiformis in the bicultures at natural density is lost when biomass is constrained in the per capita treatments, i.e. biomass is not directly related to bioturbation rate.

Apparent facilitation in diversity may reflect masking or rapid destruction of the bioturbation traces of the other species by the dominant bioturbator. From our natural-density experiments it is clear that the presence of Leptopentacta elongata clearly masks the presence of Nephtys hombergii, while Amphiura filiformis masks the presence of both L. elongata and N. hombergii respectively. There may not be true facilitation here, as it is more likely that $A$. filiformis is dominating in terms of bioturbation. The rapid homogenisation of the sediment by A. filiformis destroys the signal of the other species, masking their presence.

The broader effect of species on particle reworking is perhaps better considered by taking the entire profile into consideration. While Leptopentacta elongata and Nephtys hombergii have a large biomass at the station relative to the other species present, they occur in low numbers, usually as solitary individuals. As a result, the bioturbation effect of these 2 species on the sediment is localised to their presence. Amphiura filiformis has a dominant presence at the station, in terms of both biomass and numbers. This relative proportioning between biomass and numbers means that the influence of $A$. filiformis on the sediment is much more widespread. Individuals can be seen to be well spaced throughout the time-lapse deployment, maximising their area of influence. This is evident from the MDS plot, where all the treatments containing A. filiformis were grouped together, with the effects of the other species present in the biculture treatments having very little influence on the reworking profile. 
Amphiura filiformis appears to be a key species that actively modifies its habitat and is fundamental in determining rates of particle reworking in Inner Galway Bay. An investigation into the effect of $A$. filiformis on oxygen penetration into the sediment by Vopel et al. (2003) found that it was responsible for up to $80 \%$ of oxygen uptake. This was due to its bioirrigation activities and the creation of extra subsurface area for oxygen exchange with the pore-water across its burrow walls. Solan \& Kennedy (2002) conservatively calculated that, in Galway Bay, the exposed area of burrow wall created by $A$. filiformis was $0.76 \mathrm{~m}^{2} \mathrm{~m}^{-2}$. In this study we did not attempt to make such a calculation, as the ephemeral nature of arm tunnels made the assessment very difficult.

A recent simulation of species-extinction effects on the mean depth of the apparent redox potential discontinuity (aRPD) in the inner Galway Bay (Solan et al. 2004a), based on concurrent SPI and faunal data (Kennedy et al. 2002), found that the loss of Amphiura filiformis had marked negative effects on the aRPD that could not be explained by its abundance or biomass. Simulations were clearly separated as those with A. filiformis, and those without. This is borne out by the findings of our study. Reworking activity by Leptopentacta elongata and Nephtys hombergii was far less than that by A. filiformis, even allowing for biomass to covary between treatments in the observed data.

In situ time-lapse SPI is a valuable technique for gaining insight into processes and interactions on the soft seafloor. The use of t-SPI has revealed a great deal of information about the burrowing and feeding activities of Amphiura filiformis that is not apparent from images captured from single-shot SPI deployments. The t-SPI has also helped to determine the rates of burrowing and excavation of material to form surface mounds. In combination with laboratory tracer experiments, it has highlighted the key role of $A$. filiformis as an ecosystem engineer. Further investigation is necessary to ascertain the relative importance of other potentially major bioturbators at the site. Experiments to constrain the nature of non-local reworking by $A$. filiformis, involving the use of several layers of tracer initially placed at various depths in the sediment (Boudreau \& Imboden 1987), are necessary to a further understanding of A. filiformis's role in ecosystem processes. Fluorescent time-lapse SPI (Solan et al. 2004b) may offer an approach that can be used in both field and laboratory experiments to further explore A. filiformis's bioturbation role in the community.

Acknowledgements. This work was funded by the Higher Education Authority, Ireland, under PRTLI Cycle II. We thank P.J. Walsh of seaborg Oceanics for electronic support, and J. Galvin, A. Lawless and D. Burke for technical support at sea.

\section{LITERATURE CITED}

Austen MC, Widdicombe S (1998) Experimental evidence of the effects of the heart urchin Brissopsis lyrifera on associated subtidal meiobenthic nematode communities. J Exp Mar Biol Ecol 222:219-238

Baden SP, Pihl L, Rosenberg R (1990) Effects of oxygen depletion on the ecology, blood physiology and fishery of the Norway lobster Nephrops norvegicus. Mar Ecol Prog Ser 67:141-155

Boudreau BP (1986) Mathematics of tracer mixing in sediments. II. Nonlocal mixing and biological conveyer-belt phenomenon. Am J Sci 286:81-94

Boudreau BP, Imboden D (1987) Mathematics of tracer mixing in sediments. III. The theory of nonlocal mixing within sediments. Am J Sci 287:693-719

Buchanan JB (1964) A comparative study of some features of the biology of Amphiura filiformis and Amphiura chiajei (Ophiuroidea) considered in relation to their distribution. $\mathrm{J}$ Mar Biol Assoc UK 44:565-576

Emerson MC, Solan M, Emes C, Paterson DM, Raffaelli DG (2001) Consistent patterns and the idiosyncratic effects of biodiversity in marine ecosystems. Nature 411:73-77

François F, Gerino M, Stora G, Durbec JP, Poggiale JC (2002) A functional approach to sediment reworking by gallery forming macrobenthic organisms: modeling and application with the polychaete Nereis diversicolor. Mar Ecol Prog Ser 229:127-136

Gilbert F, Hulth S, Strömberg N, Ringdahl K, Poggiale JC (2003) 2-D optical quantification of particle reworking activities in marine surface sediments. J Exp Mar Biol Ecol 285/286:251-263

Hector A (1998) The effects of diversity on productivity: detecting the role of species complementarity. Oikos 82: 597-599

Hector A, Schmid B, Beierkuhnlein C, Caldeira MC and 30 others (1999) Plant diversity and productivity experiments in European grasslands. Science 286:1123-1127

Heemsbergen DA, Berg MP, Loreau M, van Hal JR, Faber JH, Verhoef HA (2004) Biodiversity effects on soil processes explained by interspecific functional dissimilarity. Science 306:1019-1020

Houston MA, Aarssen LW, Austin MP, Cade BS and 43 others (2000) No consistent effect of plant diversity on productivity. Science 289:1255

Jolliffe PA (2000) The replacement series. J Ecol 88:371-385

Josefson AB (1995) Large scale estimate of somatic growth in Amphiura filiformis (Echinodermata: Ophiuroidea). Mar Biol 124:435-442

Keary R, Keegan BF (1975) Stratification by infaunal debris: a structure, a mechanism and a comment. J Sediment Petrol 45:241-242

Keegan BF, O'Connor B, McGrath D, Konnecker G (1976) The Amphiura filiformis-Amphiura chiajei community in Galway Bay (West coast of Ireland) - a preliminary account. Thalassia Jugosl 12:189-198

Keegan BF, Rhoads DC, Germano JD, Solan M and 9 others (2002) Sediment profile imagery (SPI) as a benthic monitoring tool - introduction to a long term case history evaluation - (Galway Bay, west coast of Ireland). In: Aller JY, Woodin SA, Aller RC (eds) Organism-Sediment interactions. Belle Baruch Library in Marine Science, University of South Carolina Press, Columbia, p 43-62

Kennedy R (2000) Animal-sediment relations in Inner Galway Bay (west coast of Ireland) with particular reference to bioturbation. PhD dissertation, National University of Ireland, Galway 
Kennedy R, Solan M, Keegan B (2002) Alternatives to quantifying macrobenthic diversity at the species level: the utility of estimating diversity from higher taxonomic levels and sediment profile imagery (SPI). In: Nunn JD (ed) Marine biodiversity in Ireland and adjacent waters. Proceedings of a local meeting of the Estuarine and Coastal Sciences Association (ECSA), Ulster Museum, Belfast, 26-27 April, 2001. Publ 8, Museums and Galleries of Northern Ireland, Belfast, p 75-92

Kruskal JB, Wish M (1978) Multidimensional scaling. Sage Publications, Beverly Hills, CA

Lawton JH (1994) What do species do in ecosystems? Oikos $71: 367-374$

Levinton J (1995) Bioturbators as ecosystem engineers: control of the sediment fabric, inter-individual interactions and material fluxes. In: Jones CG, Lawton JH (ed) Linking species and ecosystems. Chapman \& Hall, London, p 29-36

Loo LO, Jonsson PR, Sköld M, Karlsson Ö (1996) Passive suspension feeding in Amphiura filiformis (Echinodermata: Ophiuroidea): feeding behaviour in flume flow and potential feeding rate of field populations. Mar Ecol Prog Ser 139:143-155

Loreau M (1998) Separating sampling and other effects in biodiversity experiments. Oikos 82:600-602

Loreau M, Hector A (2001) Partitioning selection and complementarity in biodiversity experiments. Nature 412:7-76

Mahaut ML, Graf G (1987) A luminophore tracer technique for bioturbation studies. Oceanol Acta 10:323-328

Mermillod-Blondin F, François-Carcaillet F, Rosenberg R (2005) Biodiversity of benthic invertebrates and organic matter processing in shallow marine sediments: an experimental study. J Exp Mar Biol Ecol 315:187-209

Meysman FJR, Boudreau BP, Middelburg JJ (2003) Relations between local, non-local, discrete and continuous models of bioturbation. J Mar Res 61:391-410

Moga AN, Gabbouj M (1997) Parallel image component labeling with watershed transformation. IEEE (Inst Electr Electron Eng) Transactions on Pattern Anal Mach Intell 19:5 441-450

O'Connor B, Bowmer T, Grehan A (1983) Long-term assessment of the population dynamics of Amphiura filiformis (Echinodermata: Ophiuroidea) in Galway Bay, West Coast of Ireland. Mar Biol 75:279-286

O'Connor B, Bowmer T, McGrath D, Raine R (1986a) Energy flow through an Amphiura filiformis (Echinodermata: Ophiuroidea) population in Galway Bay, west coast of Ireland: a preliminary investigation. Ophelia 26: 351-357

O'Connor B, McGrath D, Keegan BF (1986b) Demographic equilibrium: the case of Amphiura filiformis assemblage on the west coast of Ireland. Hydrobiologia 142:151-158

Editorial responsibility: Otto Kinne (Editor-in-Chief), Oldendorf/Luhe, Germany
O'Connor B, McGrath D, Könnecker G, Keegan BF (1993) Benthic macrofaunal assemblages of greater Galway Bay. Biol Environ 93:127-136

Peterson CGJ (1913) Valuation of the sea. II. The animal communities of the sea bottom and their importance for marine zoogeography. Rep Danish Biol Stat 21:1-44

Pearson TH, Rosenberg R (1978) Macrobenthic succession in relation to organic enrichment and pollution of the marine environment. Oceanogr Mar Biol Annu Rev 16:229-311

Press WH, Flannery BP, Teukolsky SA, VeHerling W (1986) Numerical recipes. Cambridge University Press, Cambridge

Raffaelli DG, Emerson MC, Solan M, Biles C, Paterson D (2003) Biodiversity and ecosystem process in shallow coastal waters: an experimental approach. J Sea Res 49: 133-141

Rhoads DC, McCall PL, Yingst JY (1978) Disturbance and production on the estuarine seafloor. Am Sci 66:577-586

Rosenberg R (1976) Benthic faunal dynamics during succession following pollution abatement in a Swedish estuary. Oikos 27:414-427

Rosenberg R (1995) Benthic marine fauna structured by hydrodynamic processes and food availability. Neth J Sea Res 34:303-317

Rosenberg R, Selander E (2000) Alarm signal response in the brittle star Amphiura filiformis. Mar Biol 136:43-48

Rowden AA, Jago CF, Jones SE (1998) Influence of benthic macrofauna on the geotechnical and geophysical properties of the surficial sediments, North Sea. Contin Shelf Res 18:1347-1363

Solan M, Kennedy R (2002) Observation and quantification of in situ animal-sediment relations using time-lapse sediment profile imagery (t-SPI). Mar Ecol Prog Ser 43: 143-156

Solan M, Cardinale BJ, Downing AL, Engelhardt KAM, Ruesink JL, Srivastava DS (2004a) Extinction and ecosystem function in the marine benthos. Science 306:1177-1180

Solan M, Wigham BJ, Hudson IR, Kennedy R, Coulon $\mathrm{CH}$, Norling K, Nilsson HC, Rosenberg R (2004b). In situ quantification of bioturbation using time-lapse fluorescent sediment profile imaging (f-SPI), luminophore tracers and model simulation. Mar Ecol Prog Ser 271:1-12

van Duineveld GCA, Noort GJ (1986) Observations on the population dynamics of Amphiura filiformis (Ophiuroidea: Echinodermata) in the southern North Sea and exploitation by the dab, Limanda limanda. Neth J Sea Res 20:85-94

Vopel K, Thistle D, Rosenberg R (2003) Effect of the brittle star Amphiura filiformis (Amphiuridae, Echinodemata) on oxygen flux into the sediment. Limnol Oceanogr 48: $2034-2045$

Woodley JD (1975) The behaviour of some amphiurid brittlestars. J Exp Mar Biol Ecol 18:29-46

Submitted: February 18, 2005; Accepted: November 1, 2005 Proofs received from author(s): May 11, 2006 